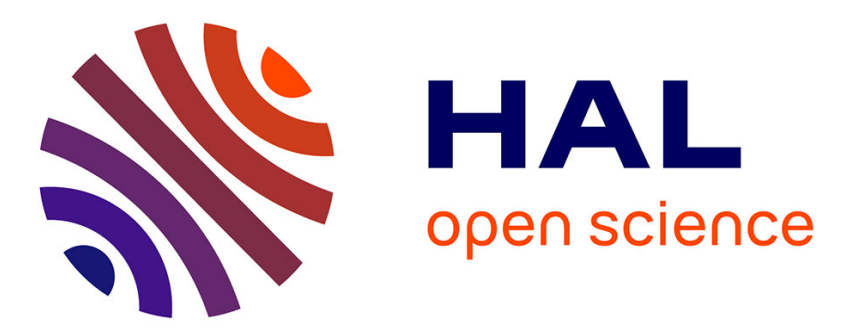

\title{
ABSOLUTE MEASUREMENT OF OPTICAL ATTENUATION USING PHOTOTHERMAL LASER-BEAM-DEFLECTION SPECTROSCOPY
}

G. Wetsel, Jr, S. Stotts

\section{- To cite this version:}

G. Wetsel, Jr, S. Stotts. ABSOLUTE MEASUREMENT OF OPTICAL ATTENUATION USING PHOTOTHERMAL LASER-BEAM-DEFLECTION SPECTROSCOPY. Journal de Physique Colloques, 1983, 44 (C6), pp.C6-215-C6-219. 10.1051/jphyscol:1983633 . jpa-00223192

HAL Id: jpa-00223192

https://hal.science/jpa-00223192

Submitted on 1 Jan 1983

HAL is a multi-disciplinary open access archive for the deposit and dissemination of scientific research documents, whether they are published or not. The documents may come from teaching and research institutions in France or abroad, or from public or private research centers.
L'archive ouverte pluridisciplinaire HAL, est destinée au dépôt et à la diffusion de documents scientifiques de niveau recherche, publiés ou non, émanant des établissements d'enseignement et de recherche français ou étrangers, des laboratoires publics ou privés. 


\title{
ABSOLUTE MEASUREMENT OF OPTICAL ATTENUATION USING PHOTOTHERMAL LASER-BEAM-DEFLECTION SPECTROSCOPY
}

\author{
G.C. Wetsel, Jr. and S.A. Stotts \\ Department of Physics, Southern Methodist University, Dalzas, \\ Texas 75275 , U.S.A.
}

\begin{abstract}
Résumé - On prësente une méthode photothermique de mesure absolue du coefficient d'absorption. Son domaine d'application est défini par un modèle thêorique.
\end{abstract}

Abstract - A method of absolute measurenent of optical attenuation using photothermal spectroscopy has been developed. Its range of applicability is characterized by a theoretical model.

We have discovered that laser-beam-deflection spectroscopy (LBDS) can be used for the absolute measurement of wave or particle-beam attenuation. 1 In this paper we report: 1) the successful application of LBDS to the absolute measurement of optical attenuation, $B$, in $U^{3^{+}}: \mathrm{CaF}_{2}$, 2) comparison of the LBDS results to determination of $B$ by enclosed-cell-microphone-detection photoacoustic spectroscopy (LCMD PAS) and by measurement of transmitted and reflected light, and 3 ) the results of a theoretical model developed to explain the experiment and characterize its range of applicability.

An exponential decrease of the intensity of a wave or partigle beam with distance (z) along the direction of wave propagation, $I(z)=I_{0} e^{-B z}$, where $I_{0}$ is the intensity at $z=0$, is characteristic of any loss process for which the spatial rate of change of intensity is linearly proportional to the intensity. If the photothermal laser-beam deflection signal is 1 inearly proportional to I(z), than a semilogarithmic plot of that signal versus 2 will be a straight line the slope of which is equal to $-B$. Such a measurement provides a direct, absolute value of attenuation -- by the definition of attenuation. This method contrasts to indirect methods in which transmitted intensity is measured or in which intensity-dependent signals are compared to a reference signal (relative measurements), and to absolute-attenuation measurements that require precise theory and knowledge of material parameters to infer $B$ from the data.

The application of laser-beam-deflection measurements to spectroscopy or photothermal laser-beam-deflection spectroscopy (PTLBDS), was first reported by Boccara, et $a 1 .^{2}$, who measured relative optical absorption as a function of wavelength for several solid samples. In subsequent studies PTIBDS was utilized to measurc the optical absorption coefficient in weakly absorbing gascous ${ }^{3}$ and condensed ${ }^{4}$ samples. The deflection signal was calibrated in the former study using a gaseous mixture of known $B$ and in the latter study using solid and liquid samples that had previously been characterized with a spectrophotometer. Photothermal laser-beam deflection has also been employed to measure thermal images of surface ${ }^{5}$ and subsurface ${ }^{6}$ structure.

The concept of absolute-attenuation measurement using IBDS was tested using a chopped Ar laser "pump" beam and a He-Ne laser "probe" beam. The pump beam at a wayelength of $514 \mathrm{~nm}$ was directed at normal incidence into $a 0.7 \times 0.7 \times 1 \mathrm{~cm}$ $\mathrm{U}^{3^{+}}: \mathrm{CaF}_{2}$ crystal. $7^{7}$ The probe beam at $633 \mathrm{~nm}$, a wavelength for which the sample is weakly absorbing, was directed perpendicular to the pump beam through the region of refractive-index gradient produced by the heat of the absorbed pump beam. Both 
parallel (z) and perpendicular (y) deflection signals were detected by a two-dimensional position sonsor. As the sample was scanned parallel to $z$ using a stepping motor, the amplitude and phase of the deflection signal wore measured by a lock-inanalyzer. The experiment was controlled and data automatically acquired using a computer.

The position-sensor signal corresponding to the component of the probe-beam deflection parallel to the direction of pump-beam propagation is shown in Fig. 1 as a function of $z$ for $f=25 \mathrm{~Hz}$. The data range extends from a point near the pumpbeam entrance surface to a point in the bulk of the sample. The semilog plot of the data is well characterized by a straight line except near $z=0$ (near the input surface). A least-squares fit of these data to a straight line yields the slope, and hence, $B$. Similar results were obtained for repeated measurements of the parallel component of deflection and for measurements of the component of deflection perpendicular to the direction of pump-beam propagation. Based on these various measurements, the most probable value of $\beta$ obtained by the PTLBDS method is $10 \mathrm{~cm}^{-1}$ for the $\mathrm{U}^{3^{+}}: \mathrm{CaF}_{2}$ sample at $514 \mathrm{~nm}$. It should be mentioned that a position-sensor voltage of $100 \mu \mathrm{V}$ corresponds to a deflection angle of $5 \times 10^{-7}$ radians.

Measurements on the same sample were made using two other independent methods for purposes of comparison with the PTLBDS result. Measurements of incident, reflected, and transmitted power at $514 \mathrm{~nm}$ were made using a photodetector and a calibrated optical attenuator. With the assumption that therc is no surface attenuation for this sample, a value of $11 \mathrm{~cm}^{-1}$ was inferred from the reflection-transmission measurements. Previously, the attenuation in this sample had been determined from ECMD-PAS experiments. 8 The ECMD-PAS signal was measured as a function of chopping frequency and the data were fit to the theory of McDonald and Wetsel ${ }^{9}$ using a computer search procedure and a provision for surface attenuation. Assuming a value for surface absorption extrapolated from the data of Hordvik and Skolnik $0^{2}$ for CaF 2 , the value estimated for $\beta$ was about $12 \mathrm{~cm}^{-1}$. A theoretical model has been developed that describes the temperature gradients produced by photothormal conversion of the

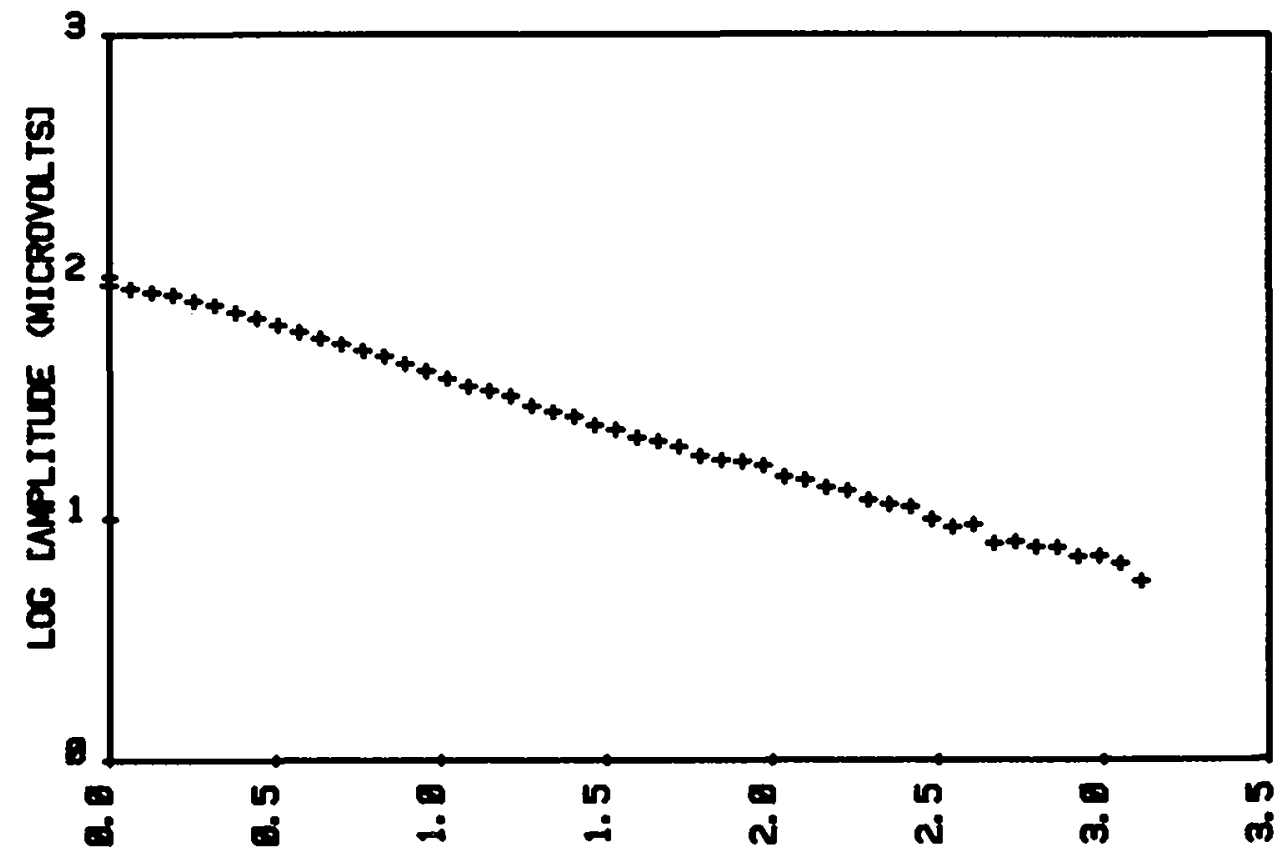

$Z$ MILLIMETERS)

Fig. 1. Position-sensor amplifier output voltage vs. $z$ for $\mathrm{O}_{\mathbf{l l}}: \mathbf{f}=25 \mathrm{~Hz}$, wavelength $=514 \mathrm{~nm}, \mathrm{U}^{3^{+}}: \mathrm{CaF}_{2}$. 
pump beam and the deflection of the probe beam for the case where the probe bean propagates in the sample perpendicular to the pump beam. The theoretical procedure is similar to that for the cases of photothermal imaging of surface and subsurface structure ${ }^{5}, 11$, and for PTLBDS when the probe beam is outside the sample!1, 12 , or propagating inside the sample parallel to the pump beam. ${ }^{2}$ The thermal diffusion equation with an axially-symmetric heat-source term characteristic of absorption from a harmonically-modulated Caussian pump beam was first solved. Then, the fuler differential equations for the optical path, derived from fermat's principle, were integrated to obtain the equations for the parallel and perpendicular deflection angles. For small angles, the expression for the angle corresponding to deflection parallel to the direction of pump-beam propagation is given by:

$$
\theta_{\boldsymbol{\mu}}=-A \beta \mathrm{e}^{-\beta z} \int_{0}^{\infty}\left\{1-\exp \left[-\left(\sqrt{\lambda^{2}+\mu^{2}}-\beta\right) z\right] \frac{\cos (\sigma \lambda) \operatorname{cxp}\left(-r^{2} \lambda^{2} / 8\right) d \lambda}{\left[\left(\beta^{2}-\mu^{2}\right)-\lambda^{2}\right]},\right.
$$

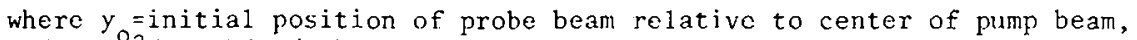
$A=\left(\alpha \beta I_{0} \mathrm{r}^{2} / 4 \mathrm{kn} O\right)(\partial \mathrm{n} / \partial \mathrm{T}), \alpha=$ fraction of absorbed light converted into heat, $r=$ Gaussian pump-beam radius, $k=$ thermal conductivity, $n_{0}=e q u i l i b r i u m$ refractive index, $(\partial n / \partial T)_{0}=$ cquilibrium refractive-index gradient, $\mu=(1+j) a \sqrt{f}, a=\left(\mu \rho C v^{i} k\right)^{1} / 2, p=$ density, $\mathrm{C}_{\mathrm{v}}$ =specific heat, and $\mathrm{f}=$ chopping frequency. A similar expression $\mathrm{is}^{\prime}$ obtained for $e_{1}$

The most important feature of $(\beta)$ vis-a-vis the absolute measurement of optical attenuation is the factor, $e^{-\beta 2}$, outsidc the integral. If the value of the integral were independent of $z$ or weakly dependent on $z$, then the functional dependence of $G_{w}$ on $z$ would be exponential or nearly exponential, respectively. The range of applicability of P'TLBDS for determining $\beta$ is then given by the range of parameters such that the second term in curly brackets of (1) is small compared to unity. Examination of that term reveals that $\theta_{\mu} \alpha \mathrm{c}^{-\beta z}$ when $\mu_{r}>B\left(\mu_{r}=R_{2}\right)$ and $z \gtrsim z_{c}$ where $z_{c}=2.3 /\left(\mu_{r}-\beta\right)^{-1}$. Numerical integration of (1) for a wide range of appropriate parameters verifies that the above inequalities provide a good measure of applicability of the method.

Calculations of $\theta_{4}$ as a function of $z$ using (1) for $z<z$ give a deviation from a straight line on a semilog plot of the same general shape as that of the data in Fig. 1; however, part of the rollover in the data near $z=0$ is due to the finite diameter of the probe beam $(20.8 \mathrm{~mm})$. Comparison of experimental and theoretical values of $\theta_{\boldsymbol{L}}(z)$ involve considerations ${ }^{\prime}$ similar to those for $\theta_{\boldsymbol{l}}(z)$, above.

As further evaluations of the model, $\theta_{\mu}$ and $\theta_{\boldsymbol{L}}$ were measured as a function of $y_{0}$. The results for the amplitude of $\theta_{1}$ are shown in Fip. 2 along with the predictions of (1). The agrecment is excellent considering that the pump beam is probably not exactly Gaussian. The experimental and theoretical variations of the phase of $E_{w}$ with $y_{0}$ were also in good agreement except for $y_{0} \mid>r$. Similarly, experimental and theoretical variations of $\theta_{\perp}$ with $y_{0}$ are in excellent agreement.

Whereas the frequency dependence of $\Theta_{\boldsymbol{N}}$ as indicated by (1) appears to be complicated, it is dominated by a $f^{-1}$ dependence, as is most photothermal phenomena. The deflection angle increases with increasing $B$ until saturation occurs; the predections of (1) for $\mathrm{CaF}_{2}$ are shown in Fig. 3 .

In summary, we have developed a method of absolute measurement of wave or particle-beam attenuation using laser-beam-deflcction spectroscopy. The experimental method and its range of applicability have been characterized by a theoretical model of PTLBDS that is in excellent agreement with the data for the test sample, a crystal of $\mathrm{U}^{3+}: \mathrm{CaF}_{2}$. The value of $\beta$ outained by PTLBDS was compared with the values obtained from two independent methods. The value of $B$ inferred from. transmission-reflection measurements is subject to errors due to surface attenuation and inhomogencity in the sample, and to calibration errors in the optical attenuators. The value of $\beta$ inferred from ECMD-PAS measurements $8,9,13$, is subject to errors due to surface attenuation and inhomogeneity in the sample, imprecise knowledge of the material parameters of the sample, and some uncertainty about the 


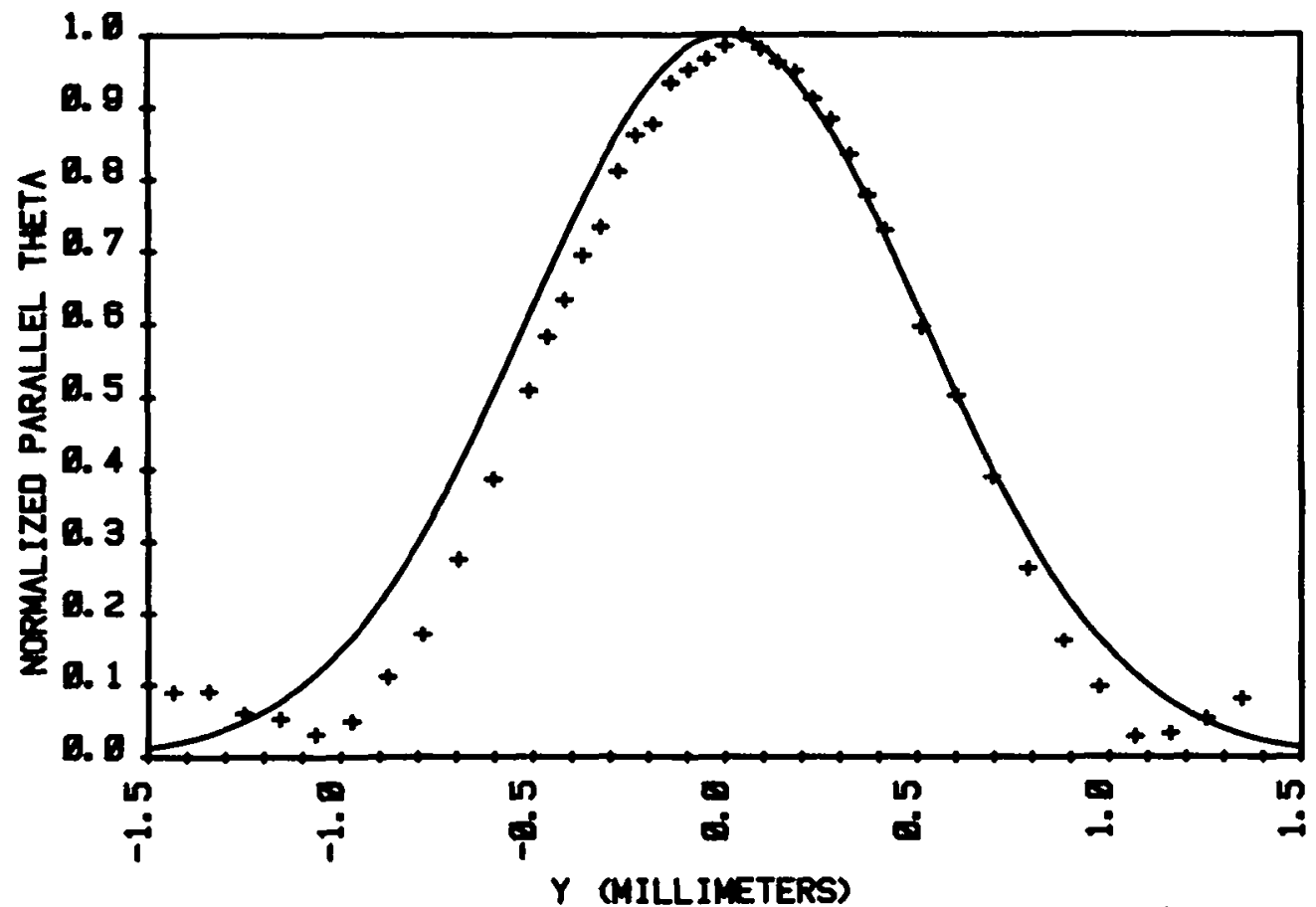

Fig. 2. Normalized $\theta_{\|}$vs. $y_{0}$ for $z=1.0 \mathrm{~mm}, f=25 \mathrm{~Hz}(+)$. Solid curve is calculated using eq. (1) with $\beta=10 \mathrm{~cm}^{-1}, r=1.0 \mathrm{~mm}$, and $\mathrm{CaF}_{2}$.

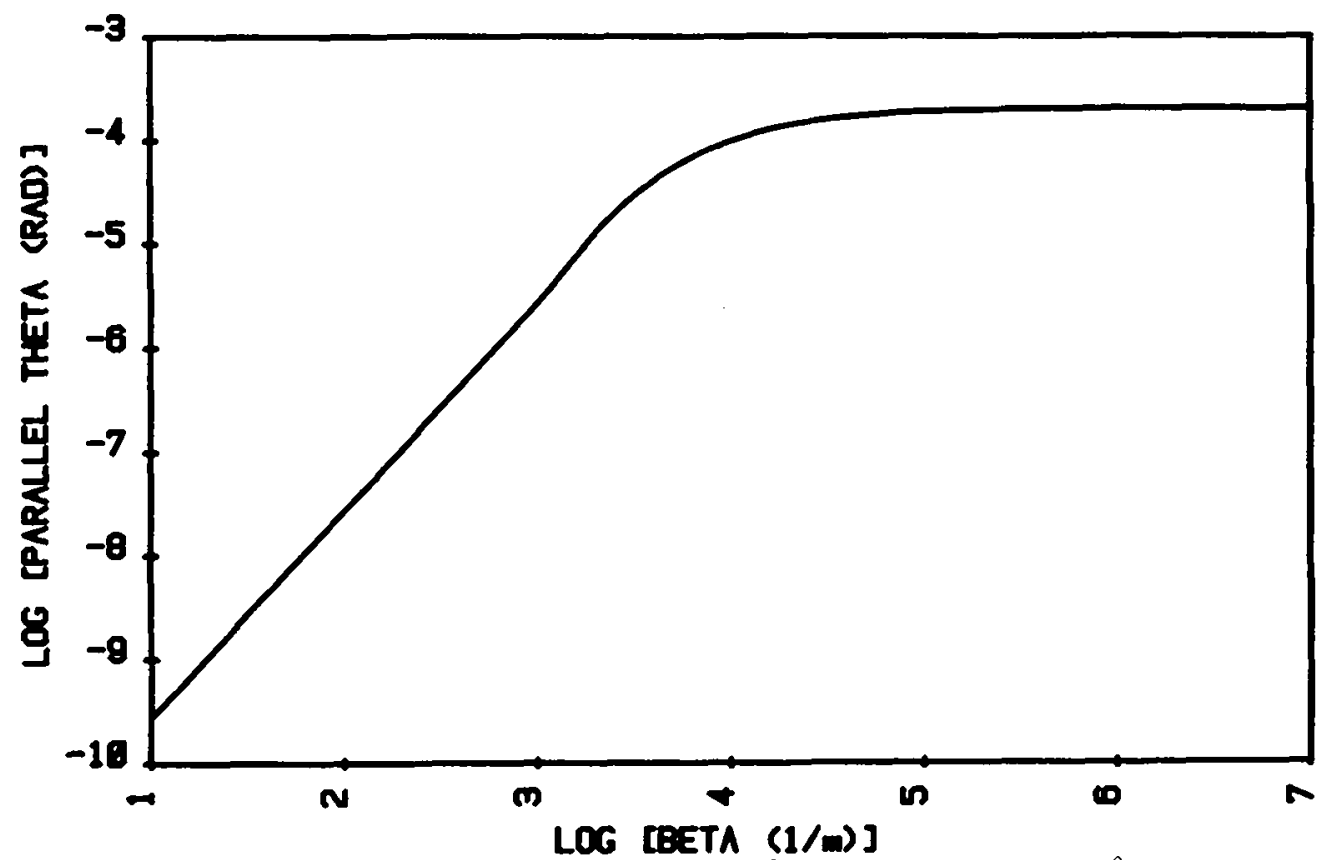

Fig. 3. Theoretical $\epsilon_{w}$ vs. $\beta: f=25 \mathrm{~Hz}, z=\beta^{-1}, y_{0}=0, I_{0}=1.0 \mathrm{~W} / \mathrm{m}^{2}$, $\mathrm{r}=1.0 \mathrm{~mm}, \mathrm{CaF}_{2}$. 
validity of the theory and computer data fitting. The LBDS technique permits the determination of attenuation by direct probing of the pump-beam intensity, $I(z)$; only the distance ( $z$ ) calibration is required. It is applicable to samples that are nearly transparent at some (probe-beam) wavelength and for which some fraction of the absorbed energy is converted into heat; yet, the measured attenuation factor, $B$, is characteristic of all processes that remove energy from the pump beam. The method is limited on the low- $\beta$ end of the range of applicability by noise and by the sample length required $\left(\sim^{-1}\right)$; it is limited on the high- $\beta$ end by the choppingfrequency dependence of the signal and hence eventually noise, and by the availability of sufficiently-small z-step size and probe-beam diameter. We expect that this range is from transparent to quite opaque for typical materials.

\section{REFERENCFS}

1. WETSEL, G. C., Jr., and STOTTS, S. A., accepted for publication in Applied Physics Letters.

2. Boccira, A. C., fournile, D., and Badoz, J., App1. Phys. lett. 36,130 (1980)

3. FOURNIER, D., BOCCARA, A. C., AMER, N. M., and GerlaCh, R., Appl. Phys. Lett. 37, $519(1980)$.

4. BOCCARA, A. C., FOURNIER, D., JACKSON, W., and AMiR, A. M., Opt. l.ett. $\underline{5}, 377$ (1980).

5. FOURNIFR, D., and BOCCARA, A. C., pp. 347-351, Scanned Image Microscopy, ASI, E. A., Ed., Academic Press, London (1980); MURPIIY, J. C., and AAMODT, L. C. App1. Phys. Lett. 38, 196 (1981); MURPHY, J. C. and MMOD', L. C., Appl. Phys. Lett. $39,519(198 \overline{1)}$.

6. WFISLL, G. C., Jr. and MCDONMID, F. A., App 1. Phys. Lett 41, 926 (1982). MCDONALD, F. A., WETSF.L, G. C., Jr., and STO'TTS, S. A., "Scanned Photothermal Imaging of Subsurface Structure", Proc. 12'th Inter. Symp on Acoustical Imaging, Plenum, London (1982).

7. The sample was kindly provided by Dr. W. A. Heargreaves, of Optovac, Inc. No. Brookfield, Mass.

8. MCDONALD, F. A., and WETSFL, G. C. Jr., "Physics of Signal production in Enclosed-Ce11 Photoacoustic Spectroscopy of Condensed Matter", Tech. Digest of the 2nd Inter. Top. Mtg. on Photoacoustic Spectroscopy, Opt. Soc. of Amer., Washington, D. C. (1981).

9. MCDONAI.D, F. A. and WETSF, , C. C., Jr., J. Appl. Phys. 49, 2313 (1978)

10. HORDVIK, A., and SKOLNIK, I., Appl. Opt. 16, 2919 (1977).

11. MURPHY, J. C., and AAMOUT, L. C., J. Appl. Phys. 51, 4580 (1980); AAMODT, L. C. and MURPhy, J. C., J. App1. Phys. 52, 4903 (1981)

12. JACKSON, W. B., MMER, N. M., BOCCARA, A. C., and FOURNIER, D., Appl. Opt. 20, $1333(1981)$.

13. WeTSEL, G. C., Jr., and MCDONALD, F. A., Appl. Phys. lett. 30, 252, (1977). 